\title{
Performance evaluation of a plate type (HTST) milk pasteurizer
}

\section{D.A. CHAUDHARY AND A.G. CHAUDHARI}

\begin{abstract}
The performance of plate type (HTST) milk pasteurizer was analyzed in a commercial dairy plant having installed capacity of 1.0 lakh lit./day. The purpose of the analysis was to determine the regeneration efficiency and utility usage includes steam, chilled water and electrical energy, in the milk pasteurization processing line. In this dairy plant, the experiment was carried out and results in 89.34 per cent regeneration efficiency achieved. Theoretical and actual steam consumption was determined at rate of $155.72 \mathrm{~kg} / \mathrm{hr}$ and $156.48 \mathrm{~kg} / \mathrm{hr}$, respectively. Chilled water utilization was found to be $25.11 \mathrm{~m}^{3} / \mathrm{hr}$ i.e. 2.36 times than milk flow rate. Power consumption for milk pasteurization was found to be $16.09 \mathrm{kWh}$ per hour.
\end{abstract}

KEY WORDS : Milk pasteurizer, HTST, Steam, Chilled water, Electrical energy

How TO CITE THIS PAPER : Chaudhary, D.A. and Chaudhari, A.G. (2015). Performance evaluation of a plate type (HTST) milk pasteurizer. Res. J. Animal Hus. \& Dairy Sci., 6(2) : 130-134. 